\title{
Anaerobic performance in masters athletes
}

\author{
Peter Reaburn • Ben Dascombe
}

Received: 25 July 2008 /Accepted: 22 November 2008 / Published online: 9 December 2008

(C) EGREPA 2008

\begin{abstract}
With increasing age, it appears that masters athletes competing in anaerobic events (10-100 s) decline linearly in performance until 70 years of age, after which the rate of decline appears to accelerate. This decline in performance appears strongly related to a decreased anaerobic work capacity, which has been observed in both sedentary and well-trained older individuals. Previously, a number of factors have been suggested to influence anaerobic work capacity including gender, muscle mass, muscle fiber type, muscle fiber size, muscle architecture and strength, substrate availability, efficiency of metabolic pathways, accumulation of reaction products, aerobic energy contribution, heredity, and physical training. The effects of sedentary aging on these factors have been widely discussed within literature. Less data are available on the changes in these factors in masters athletes who have continued to train at high intensities with the aim of participating in competition. The available research has reported that these masters athletes still demonstrate agerelated changes in these factors. Specifically, it appears that morphological (decreased muscle mass, type II muscle fiber atrophy), muscle contractile property (decreased rate of force development), and biochemical changes (changes in enzyme activity, decreased lactate production) may explain the decreased anaerobic performance in masters athletes.
\end{abstract}

\footnotetext{
P. Reaburn $(\bowtie)$

Department of Health and Human Performance,

Central Queensland University,

Bruce Highway,

Rockhampton, Queensland 4702, Australia

e-mail: p.reaburn@cqu.edu.au

B. Dascombe

Athlete and Coach Services, Western Australian Institute of Sport, Challenge Stadium, Stephenson Avenue,

Mt Claremont, WA 6010, Australia
}

However, the reduction in anaerobic work capacity and subsequent performance may largely be the result of physiological changes that are an inevitable result of the aging process, although their effects may be minimized by continuing specific high-intensity resistance or sprint training.

Keywords Anaerobic $\cdot$ Masters athletes $\cdot$ Aging

\section{Introduction}

During recent decades, there has been an increase in the number of older individuals engaging in regular physical activity and exercise for the health benefits of decreasing both morbidity and all-cause mortality [118, 143]. An increasing proportion of these active older individuals are becoming recreational or competitive athletes focused on sports performance. For example, the inaugural World Masters Games held in Toronto, Canada had 8,305 participants across 22 sports; the 2002 Melbourne, Australia World Masters Games 24,886 participants across 26 sports, and the upcoming 2009 World Masters Games being held in Sydney, Australia anticipating the biggest mass participation $(30,000)$, multi-sport (28 sports), multinational, festival in the world (Holm, personal communication, 2008). Each sport's national or international governing body determines the age to define a masters athlete. Internationally, masters' competition in swimming begins at age 25 years, track and field at 35 years, and golf at 50 years. In general, masters athletes are over the age of 40 years and may be either highly conditioned and experienced competitive athletes who have completed their formal competitive careers, the "weekend warriors" who sporadically train and compete, or older competitors 
who have resumed physical training after long periods of physical inactivity [104]. For the purposes of this paper, masters athletes are individuals who systematically train for, and compete in, organized forms of competitive sport specifically designed for older adults [127].

While the factors contributing to the age-related reduction in endurance performance have been widely examined in the masters athlete $[127,145,146]$, there is a paucity of literature examining the age-related decline in anaerobic performance observed in masters athletes or the factors that contribute to this decline in aging athletes. To our knowledge, the current review is the first to systematically examine anaerobic performance in masters athletes.

For the purposes of this paper, anaerobic performance is defined as the work capacity or sports performance during maximal exercise lasting from about $10 \mathrm{~s}$ (e.g., $25 \mathrm{~m}$ sprint swim, $100 \mathrm{~m}$ sprint run) to approximately $100 \mathrm{~s}$ (e.g., $100 \mathrm{~m}$ sprint swim, $400 \mathrm{~m}$ sprint run). Anaerobic energy production involves the replenishment of adenosine triphosphate (ATP) from both the creatine kinase and adenylate kinase pathways (ATP-PCr system), as well as the glycogenolysis and glycolysis pathways (lactic system). In order to systematically inform the current review, the determinants of anaerobic performance proposed by Bouchard, Taylor, Simoneau, and Dulac [23] will be examined in turn. Specifically, these investigators proposed that anaerobic performance is dependent upon a number of factors including:

1. Gender

2. Muscle mass

3. Muscle fiber type

4. Muscle fiber size

5. Muscle architecture and strength

6. Substrate availability

7. Efficiency of metabolic pathways

8. Accumulation of reaction products

9. Aerobic energy system contribution

10. Heredity

11. Physical Training

\section{Declines in anaerobic work performance}

Previous research on nonathletic aging individuals has demonstrated age-related declines in anaerobic work performance using cycle ergometry [102, 103, 105]. Taken together, these studies suggest an age-related decline of 6$8 \% \cdot$ decade $^{-1}$ in 30 -s work capacity in healthy aging individuals.

Few studies have used cycle ergometry to examine agerelated declines in anaerobic work performances in masters athletes using cycle ergometry [126]. While we observed age-related declines in both 10- and 30-s work performance in state-national level track and field athletes using airbraked cycle ergometry, the heterogenous nature of the subject pool (male/female, track/field, power/endurance) and small numbers of subjects per age group prevented statistically based conclusions to be drawn [126].

Numerous studies have conclusively shown a linear agerelated decline in actual anaerobic sports performance between the ages of 35 and 65-70 years, followed by a quadratic decline in masters athletes from both track and field $[11,18,48,58,88,89,113,114,142,158]$ and swimming $[14,41,48,61,68,124,144]$. In support of these age-related declines in both sprint swimming and running performance, the current world and Australian national $(25 \mathrm{~m} \mathrm{swim})$ records display similar patterns of decline with age (Figs. 1 and 2).

Donato and others [41] conducted a 12-year longitudinal study of high-performance US Masters swimmers and observed a significant linear $3-8 \% \cdot$ decade $^{-1}$ increase in $50 \mathrm{~m}$ swim time for both men and women until 70 years of age. Following this, the trend became quadratic as a group and greater in women $\left(15-16 \% \cdot\right.$ decade $\left.^{-1}\right)$ than men (13$14 \% \cdot$ decade $\left.^{-1}\right)$. Similarly, Korhonen and others [89] reported that the Records Committee of World Masters Athletics observed $100 \mathrm{~m}$ sprint running performance to slow by approximately $7 \% \cdot$ decade $^{-1}$ in men and $9 \% \cdot$ decade $^{-1}$ in women between the ages of 40 and 80 years. Within their biomechanical analysis of 70 finalists aged 35
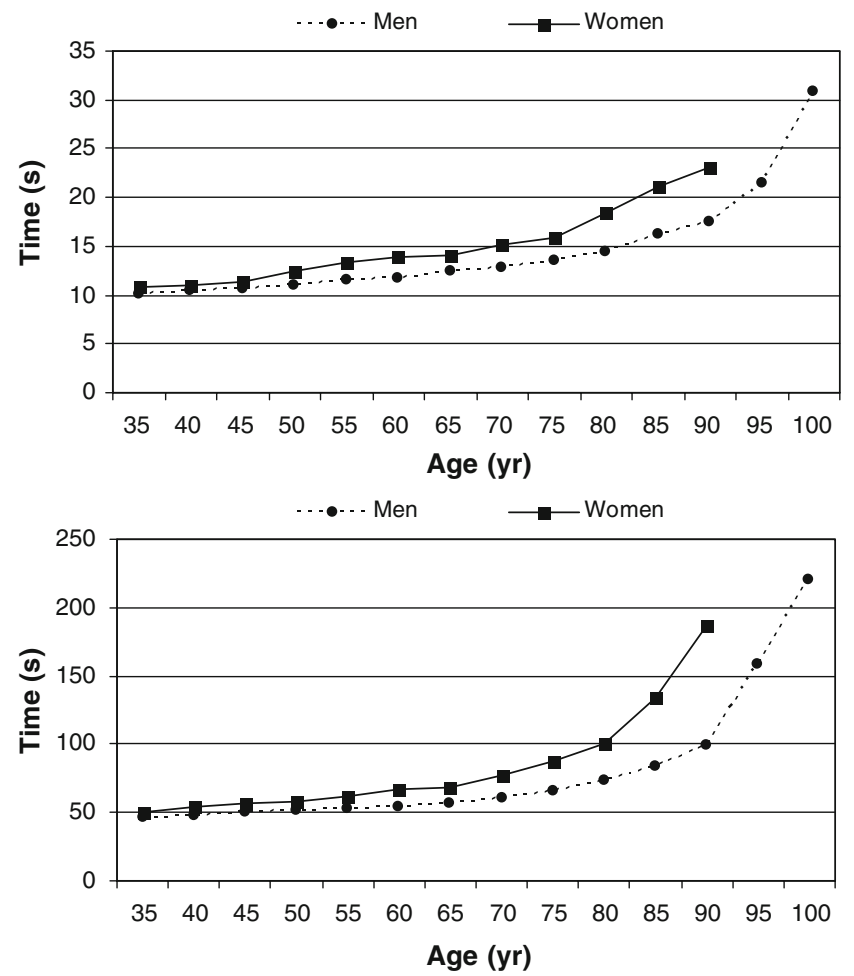

Fig. 1 World records for the 100-m (top) and 400-m (bottom) track running events in men and women with respect to age 


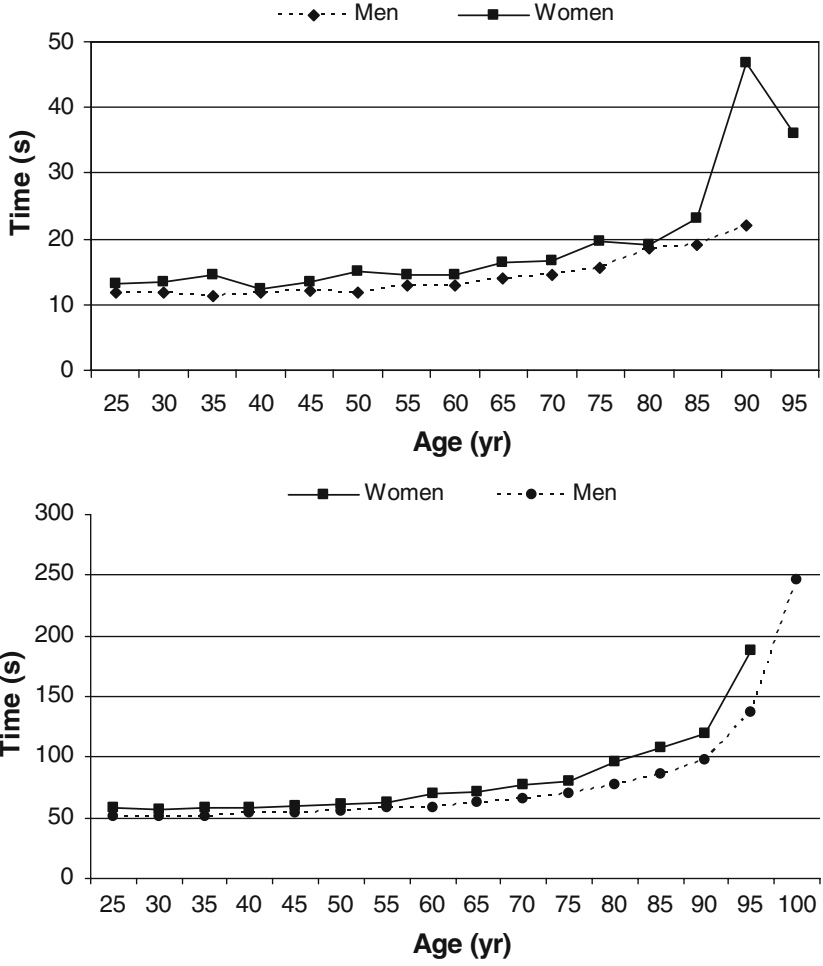

Fig. 2 Australian short-course records for the 25-m (top) and world records for the 100-m (bottom) freestyle swimming in men and women with respect to age

to 88 years, the same research team observed an exponential $5.8 \% \cdot$ decade $^{-1}$ (men) and $6.9 \% \cdot$ decade $^{-1}$ (women) decline in $100 \mathrm{~m}$ sprint run velocity in masters track athletes competing at the European Veterans Athletics Championships. Similar to findings from sprint swimming [14, 41, 48, 68] and running [11, 48], Korhonen el at. [89] reported that the effect of age was magnified after 6570 years of age. The age-related decrease in both anaerobic work performance measured using cycle ergometry and sports performance in masters athletes may be due to changes in one or more of the factors that influence anaerobic performance.

\section{Factors affecting anaerobic performance}

In younger individuals, Bouchard, Taylor, Simoneau, and Dulac [23] suggested that anaerobic capacity may be influenced by a number of factors, which have since been supported by further research. These include gender [103, 137, 154, 155], total muscle mass [120], fiber type and cross-sectional area [12, 87], physical training [102], substrate availability [107], accumulation of reaction products [40], the oxygen uptake system [69], and heredity $[19,139]$. At present, the mechanisms responsible for an age-related decline in anaerobic performance remain to be elucidated but may be due to age-related changes in any or all of the factors above.

\section{Gender}

In general, men appear to perform better than women in either accumulated oxygen deficit tests $[106,154,155]$ or $10-, 30-$ and $90-$ s anaerobic tests $[23,120]$, with female total work outputs relative to body mass being approximately $25 \%$ lower than that of men. In laboratory-based anaerobic tests, older men also perform significantly better than similar-aged women [103, 137]. Similarly, the anaerobic sports performance of elite male masters athletes in both swimming (25 and $100 \mathrm{~m})[41,48,144]$ and track and field (100 and $400 \mathrm{~m})$ [11, 48, 89, 158] is consistently $10-20 \%$ better than that of elite women of the same age (Figs. 1 and 2) between the ages of 35 and 70 years. Interestingly, the actual rate of age-related decline in sprint performance is similar in both men and women from 35 to 70 years at $5-10 \% \cdot$ decade $^{-1}[89,158]$. Following this (>70 year), it appears that masters female sprint performances in both track and field [11, 48, 89, 158] and swimming [41, 48, 144] decline significantly faster than men, with the decline reaching $40 \% \cdot$ decade $^{-1}$ by 90 years of age.

The major mechanism explaining this gender difference in anaerobic performance appear to be primarily related to gender differences in muscle mass across all age groups but which accelerates in older women after 60 years of age [76, $77,120]$. In both untrained $[12,75,154,155]$ and trained $[12,120,156]$ younger individuals, it appears that anaerobic capacity is higher in men when expressed relative to total body mass or to active muscle mass. For example, a recent study observed a $22 \%$ higher lean-mass normalized mean power output in young men compared to young female physical education students who undertook a 30-s Wingate test [120]. This would suggest that, apart from a lower active muscle mass, other gender-related factors explain the observed differences in anaerobic performance.

In younger individuals, it has been observed that, relative to similar-aged men, women display:

- Lower peak blood and muscle lactate following anaerobic performance $[62,154]$

- Decreased anaerobic enzyme activity $[27,78]$

- Decreased type II fiber size $[78,110]$

- Decreased muscular strength [122]

- Decreased $\mathrm{VO}_{2} \max$ [157]

- Decreased glycolytic contribution to anaerobic performance [71]

- Decreased peak muscle oxidative capacity [17]

The limited data available suggest that both men and women can both increase their anaerobic capacities signif- 
icantly in response to anaerobic training [98, 155]. However, it appears that, at least in younger individuals, men may be able to concurrently develop their aerobic capacity to a greater extent than women when undertaking anaerobic interval training [155].

Few studies have examined gender differences in the factors that affect anaerobic performance of older individuals, particularly masters athletes. However, it appears that relative to similarly aged men, women exhibit:

- Similar rates of decline in muscle size and strength [159-161]

- Greater rates of type II fiber atrophy [32]

- Lower peak blood lactates following anaerobic performance $[14,90]$

- Decreased estrogen levels that affect muscular performance [130]

Taken together, the age-related rate of decline in anaerobic performance is similar in both male and female athletes until approximately 70 years of age after which women's performance, possibly for sociological factors, declines at a faster rate. Apart from the well-documented differences (e.g., muscle mass, muscular strength, aerobic capacity) observed between the genders, it appears that both the greater rate of type II fiber atrophy and hormonal changes may explain the gender-related differences in both anaerobic performance and its rate of decline observed in older athletes.

\section{Muscle mass}

Muscle mass is highly related to both maximal 30-s cycle ergometry performance and $300 \mathrm{~m}$ sprint performance in both young men and women [120]. In an older healthy population, Makrides and others [103] observed that total work performed during a maximal 30 -s cycle ergometry test in 100 older sedentary men and women was strongly related $(r=0.84)$ to lean thigh volume estimated anthropometrically. Such data strongly suggest that active muscle mass, at least in older sedentary individuals, is related to maximal short-term anaerobic performance.

An age-related decline in active muscle mass is a consistent finding in aging nonathletic individuals [77, 99, $115]$, and both endurance-trained $[67,86,126]$ and sprinttrained masters athletes [88]. Lexell, Taylor and Sjostrom [100], in their classic cross-sectional autopsy study, observed a modest $10 \%$ decrease in muscle size between 24 and 50 years of age that had accelerated to $30 \%$ between 50 and 80 years of age. Two recent 9- to 12-year longitudinal studies by Frontera and others $[54,57]$ used computerized tomography to demonstrate a significant agerelated reduction in cross-sectional area of the total anterior muscle compartment of the thigh. These data strongly suggest that the loss of muscle mass with age despite continued training contributes to the decline in anaerobic performance in aging athletes.

In contrast, there exists some evidence to suggest that older strength-trained athletes may be able to maintain muscle mass with age [86, 119], while older endurance athletes appear not to be able to maintain muscle mass [153]. For example, Klitgaard et al. [86] found that elderly men ( $68 \pm 0.8$ years) with $12-17$ years of heavy resistance training three times a week had muscle fiber sizes similar to young adult ( $28 \pm 1.0$ years) sedentary controls. In contrast, Trappe and others [153] observed that older distance runners (68.4 \pm 2.7 years), despite having maintained high levels of physical training for 20-25 years, possessed similar muscle cross-sectional areas to age-matched sedentary men. More recently, a group of Scandinavian researchers undertaking extensive cross-sectional, longitudinal, and intervention studies on elite masters athletes observed a general increase in muscle fiber areas and significant increase in type IIA fiber area in elite masters sprinters ( $66 \pm 3$ years; $32 \pm 7$ training years) who undertook a 20 -week training program consisting of combined sprint training and heavy and explosive strength exercises [88]. While anaerobic performance was not directly measured using ergometry, significant increases were reported for strength, explosive jump performance, rate of force development, stride length, as well as $10 \mathrm{~m}$ and $60 \mathrm{~m}$ sprint run performance. These data support another recent Scandinavian study that compared types I, IIA, and IIX muscle fiber areas of elderly (68-78 years) endurance- and strength-trained athletes who were chronically trained for over 50 years [1]. Both muscle fiber size and mechanical muscle performance, especially rate of force development, were elevated in those individuals exposed to lifelong strength training. Taken together, the above data suggest that heavy resistance training combined with high power exercises may help prevent decreases muscle mass through type II fiber atrophy and in turn, losses in explosive muscle force production and decreased anaerobic performance in masters athletes.

\section{Muscle fiber type}

The age-related decrease in muscle mass may be due to a reduction in muscle fiber number, a reduction in fiber crosssectional area, or both $[49,99]$. Perhaps the least controversial finding in studies of aging human skeletal muscle is the loss of muscle fiber numbers with increasing age [99]. Direct evidence for loss of muscle fibers has been obtained by counting muscle fibers in autopsied whole vastus lateralis muscle in previously healthy individuals aged between 15 to 83 years [99]. These researchers noted a reduction in the total number of muscle fibers with no apparent effect for a particular fiber type. It has been 
suggested that the aging process is accompanied by fiber type redistribution with the number of type I fibers increasing at the expense of type II fiber number. This is supported by needle biopsy studies that suggest the ratio of type II to type I fiber areas in the vastus lateralis decreases with age in healthy, nonathletic individuals, particularly during the seventh decade of life [5, 45, 94, 96, 97, 99]. More recently, Korhonen et al. [88] observed no age-related differences in fiber type distribution when comparing the types I, IIA, and IIB fiber composition of young (1833 years) and older (53-77 years) national and international level sprint runners. These data agree with earlier findings from our laboratory where no significant difference in fiber composition was observed between chronically ( $>35$ years) trained sprint- or endurance-trained masters runners and training volume and body mass-matched younger runners [126]. However, when Korhonen et al. [88] combined the fiber composition data with the corresponding fiber area to form the relative fiber type area, there was an age-related increase in type I fiber area and a trend towards a decrease in the area of type IIB fibers with age based on traditional myosin-ATPase histochemical staining techniques. Moreover, using gel electrophoretic techniques, the same study revealed an age-related increase in the single muscle fiber relative content of myosin heavy chain (MHC) I and a decrease in MHC IIx expression with age. Taken together, these finding suggest that highly trained masters sprint runners experience the normal age-related decrease in relative type II fiber area and a shift towards a slower MHC isoform profile that plays a major role in the rate of force development within muscles involved with anaerobic performance.

\section{Muscle fiber size}

In both young nonexercising and athletic individuals, a significant correlation is commonly observed between $30-\mathrm{s}$ maximal exercise performance and both type II fiber composition and cross-sectional area. Thus, an age-related decrease in type II fiber area would be expected to negatively affect anaerobic performance in older individuals. In sedentary aging individuals, one of the most consistent findings is an age-related decrease in the size of type II muscle fibers [4, 26, 39, 100]. Lexell and others [100] observed no decrease in type I fiber size but reported a decrease in the type II muscle fiber cross-sectional area by $26 \%$ in individuals aged between 20 and 80 years. However, older athletes appear to slow the rate of this age-related decline in type II fiber area through engaging in high-intensity resistance and sprint training [1, 34, 88, 137].

It appears that there is preferential age-related atrophy among the different type II fibers in sedentary aging individuals [6, 32]. For example, Coggan and others [32] examined ten men and ten women (64 11 years) and ten men and ten women ( $24 \pm 1$ years) and observed a greater atrophy in the type IIB (22\% male, $30 \%$ female) than the type IIA ( $13 \%$ male, $24 \%$ female) fiber. Recent evidence from Korhonen and others [88] would suggest that, while aging sprint runners exhibit significant age-related declines in the cross-sectional area of the different type II muscle fibers, the declines were not different for type IIA $\left(6.7 \% \cdot\right.$ decade $\left.^{-1}\right)$ or type IIB $\left(11.3 \% \cdot\right.$ decade $\left.^{-1}\right)$.

In masters athletes, it appears that neither chronic endurance training [67, 86, 123] or sprint training [88] can prevent the age-related loss of muscle mass associated with a decrease in type II fiber size. In contrast, recent studies suggest that strength, explosive power and/or sprint training in masters athletes may prevent the commonly observed age-related decrease in type II fiber size in aging nonathletes $[1,34,88]$. Recent evidence from Korhonen and others [88] demonstrated that, while aging sprint runners exhibited significant declines in the cross-sectional area of type II muscle fibers, the declines were not different for type IIA $\left(6.7 \% \cdot\right.$ decade $\left.^{-1}\right)$ or type IIB $\left(11.3 \% \cdot\right.$ decade $\left.^{-1}\right)$. Taken together, these recent data suggest that high intensity sprint training combined with power and strength training into older age may help reduce the decrease in type II fiber size and thus possibly slow the age-related decline in anaerobic performance commonly observed in masters athletes. Interestingly, beyond $65-70$ years of age, a dramatic reduction in fiber size appears evident in all fiber types but particularly type IIA and IIB [6, 32, 45, 94, 99]. While there exists little evidence of similar declines in masters athletes over 70 years of age, Korhonen and others [88] recently observed significantly larger type I fibers than type IIB fibers in 60-plus year-old sprint runners compared to younger runners $18-59$ years of age. This finding may help explain the quadratic versus linear rates of decline in anaerobic sports performance in the older age groups (>70 years) within both swimming and track and field cohorts discussed earlier.

Thus, it would appear that the majority of available evidence suggests that the atrophy of skeletal muscle during aging in masters athletes appears to be caused by reduction in both the size and number of the skeletal muscle fibers. It also appears that the reduction in fiber size occurs mainly in the type II fibers. Taken together, these declines may contribute strongly to the age-related decline in anaerobic performance observed in masters athletes.

Muscle architecture and strength

In addition to muscle cross-sectional area, a muscle's geometry (angles and lengths of the muscle's fibers or fascicles) strongly influences force production (strength) and, in turn, anaerobic performance [16, 23, 24]. For 
example, both vastus lateralis and gastrocnemius of highly trained young male sprinters $(100 \mathrm{~m}$ in $<11.0 \mathrm{~s})$ contained longer fascicles attached at smaller angles than in lessperformed sprinters $(100 \mathrm{~m}$ in $>11.0 \mathrm{~s})$ [2]. In contrast, it appears that well-trained young endurance-trained runners have shorter fascicles and greater fascicle angles than highperformance sprint runners [2]. Changes in muscle architecture have been proposed to partially explain the decreases in muscular strength associated with aging [16, 149]. The limited data available suggests that normal aging is accompanied by both a decrease in both fascicle angle and length that appear to accompany the well observed decrease in muscle mass in sedentary aging individuals [16]. However, it appears that heavy and long-term weight training may attenuate this decline, at least in fascicle length [16]. A recent study investigated the contribution of muscle architecture to both isometric and isokinetic torquevelocity and power-velocity relationships between older (69-82 years) and younger (19-35 years) men [149]. Decreases in muscle cross-sectional area, fiber fascile length, together with a change towards slower MHC composition accounted for age-related decreases in both muscle strength and power in the older men. Therefore, together with changes in fiber number and area, changes in muscle architecture may also contribute to strength declines with age and thus anaerobic performance.

Muscular strength in both young athletes [8] and older strength-trained individuals [137] has been reported to be significantly correlated with performance in the Wingate 30 -s anaerobic test, suggesting that muscular strength is important to anaerobic performance. Cross-sectional studies suggest muscular strength peaks at approximately 30 years of age and is well maintained to 50 years of age [96], declines gradually between 50 and 60 years, and rapidly declines thereafter [96]. This rapid decline in muscular strength of up to $2.5 \%$ per year after 60 years of age is strongly supported by a number of longitudinal studies on men aged over 60 years $[6,53,56]$.

A similar observation has also been made by Alway and others [3] who observed a loss of muscle strength in older endurance-trained athletes relative to untrained younger men. Results from our laboratory also suggest a decrease in knee extensor isokinetic strength in aged sprint and endurance runners ( $>60$ year) compared to younger $(20$ 25 years) runners matched for body mass, training status, and training volume [126]. The age-related decrease in lower body muscular strength of older athletes may therefore contribute to the age-related declines in anaerobic performance observed in masters athletes.

Neural factors may also play a role in the age-related decline in both muscular strength and anaerobic performance in masters athletes. The specific tension (force per unit cross-sectional area) of whole muscle appears to decline with age in sedentary aging individuals $[35,66$, 161] but is maintained in older sprint athletes [88]. However, in elite masters sprint runners, the rate of force development (RFD) has recently been shown to decrease significantly with age at approximately $9.7 \% \cdot$ decade $^{-1}$, with the time taken to reach peak RFD almost doubling between the 18-33 years group and the $>70$ years group in the same cohort [88]. Crucially, both the RFD and time taken to reach peak RFD were significantly related to MHC II isoform content, which decreased significantly with age while MHC I isoform content significantly increased with age. Thus, it appears that in masters sprint runners there is a slowing of muscle contractile velocity due to age-related increases in muscle cells expressing the slow MHC isoform, a finding commonly observed in sedentary aging individuals $[35,91]$.

From these studies, age-related changes in muscle architecture, muscular strength, and neural activation may help to explain the observed decline in anaerobic performance with age, even in trained masters athletes.

\section{Substrate availability}

The availability of the substrates phosphocreatine ( $\mathrm{PCr}$ ) and glycogen has also been suggested to influence anaerobic performance, as they both significantly decrease during maximal exercise lasting between 10 and $30 \mathrm{~s}$ and beyond [23]. Intramuscular concentrations of $\mathrm{PCr}$ in the vastus lateralis have been shown to be 5\% lower in older sedentary men and women (52-79 years) compared with younger adults (18-36 years) [111]. Furthermore, the same researchers reported similar trends in the total nucleotide pool, despite no such age effect in resting ATP or adenosine monophosphate concentrations. In support, McCully and others [108] reported a small but significant age-related decrease in the ratio of $\mathrm{PCr}$ to inorganic phosphate using magnetic resonance spectroscopy. Interestingly, Moller and Brandt [112] exercised seven 61- to 80-year-old, apparently healthy male subjects on a cycle ergometer twice weekly for 6 weeks. Following the training period, the ratio between $\mathrm{PCr}$ and total creatine increased, and a small but significant rise was observed for the ATP/adenosine diphosphate (ADP) ratio. The researchers concluded that age-related changes of intramuscular phosphagens in elderly subjects may in part be due to physical inactivity. While these data suggest that these changes in high energy substrates may also contribute to the age-related decrease in anaerobic performance observed in a sedentary aging population, no data have detailed the effects of age on the $\mathrm{PCr}$ availability in well-trained older athletes. Limited research has examined the effects of age on glycogen concentrations within the musculature of aging sedentary populations or masters athletes. However, glycogen, the 
substrate of anaerobic glycolysis, has been shown to also significantly decline with age in sedentary populations [30, $109]$ with muscle glycogen levels being $61 \%$ higher in sedentary 24-year-old men compared to sedentary 65 -yearold men [109]. Previous research has shown that glycogen content significantly correlated with the glycogen synthase protein content that in turn correlated inversely with age [133]. In summary, declines in the availability of the major substrates used in anaerobic performance may contribute to age-related declines in anaerobic performance observed in masters athletes. However, the possible contribution of the reduction in these substrates to the decline in anaerobic performance observed in masters athletes remains unknown.

\section{Efficiency of metabolic pathways}

The anaerobic energy systems refer to the breakdown of stored PCr and ATP, as well as the breakdown of glucose and glycogen to lactic acid via glycolysis without consuming oxygen [157]. These processes are reliant upon several enzyme-catalyzed reactions in order to occur, and thus any age-related changes in the activity of these enzymes may limit the rate at which energy can be produced anaerobically.

The enzyme creatine kinase (CK) catalyzes the reaction in which the phosphate group from $\mathrm{PCr}$ is transferred to $\mathrm{ADP}$, with the formation of adenosine triphosphate in a reversible reaction. The amount of $\mathrm{PCr}$ stored in the muscle only permits maximal exercise of 5 to $10 \mathrm{~s}$ and is thus used in events such as the $100-\mathrm{m}$ sprint run or $25-\mathrm{m}$ sprint swim [136]. Single-muscle-fiber studies have demonstrated that fast-twitch fibers are favorable for rapid energy production during high-intensity sprint exercise. These fibers possess higher basal $\mathrm{PCr}$ content and consume more of their $\mathrm{PCr}$ stores during sprinting than slow-twitch fibers [63, 148]. Moreover, fast-twitch fibers are rich in key glycolytic enzymes and produce more lactic acid than slow-twitch fibers [47, 147].

CK has recently been shown to be $21 \%$ lower in the obliquus internus abdominis muscle of older (61-74 years, $n=11)$ men compared to middle-aged (29-054 years, $n=13$ ) men [80]. This finding supports previous data that observed age-related decreases in $\mathrm{CK}$ in human skeletal muscle [141]. In contrast, a number of previous studies have observed no age-related change in CK activity in weightbearing muscles such as vastus lateralis [17], gastrocnemius [32], or ankle dorsi flexors measured using phosphorous magnetic resonance spectroscopy [93]. Of interest in the Lanza and others [93] study is that both the rate of $\mathrm{PCr}$ hydrolysis during the first $6 \mathrm{~s}$ of a 60 -s maximal isometric contraction of the ankle dorsi flexors and the overall and peak glycolytic rate were significantly faster in young (20-35 years) versus older (65-80 years) men. Within the same study, the older subjects were more reliant on oxidative ATP production more than young subjects and derived a smaller proportion of their ATP from anaerobic glycolysis during maximal voluntary isometric contractions [93].

In summary, the available data suggest that, in aging sedentary individuals, skeletal muscle $\mathrm{CK}$ and $\mathrm{PCr}$ concentrations and $\mathrm{PCr}$ hydrolysis rates are lower than those observed younger sedentary individuals. This might suggest that the capacity of the ATP-PCr system is compromised in masters athletes and that this may compromise anaerobic performance in this cohort. However, research has yet to examine this proposition.

The second energy system contributing to anaerobic performance is anaerobic glycolysis that leads to the formation of lactic acid and ATP in the cytosol and is regulated by the enzymes phosphofructokinase (PFK) and lactate dehydrogenase (LDH) [136]. Anaerobic glycolysis is the major energy system involved with events such as the 400-m sprint run or 100-m swim [157]. LDH exists in two main forms within skeletal muscle-heart-specific $(\mathrm{H}-$ LDH), which is preferentially involved in lactate oxidation to pyruvate and predominating in type I fibers, and musclespecific (M-LDH), which mainly catalyzes the reduction of pyruvate to lactate and predominates in type II fibers [136].

It is well known that type I fibers exhibit lower activities of glycolytic enzymes and produce less lactic acid than type II fibers [47, 148]. It is also known that aging in adults is accompanied by a loss of muscle mass and a shift toward a more oxidative muscle profile mediated by the atrophy of the more anaerobic type II fibers [26, 39, 122]. Indeed, Korhonen and others [88] recently observed elite masters sprint runners (53-77 years) with similar fibre composition to young (18-33 years) sprinters to demonstrate an increase in their muscle area occupied by type I fibers and decrease in the area occupied by type II fibers. These changes in the muscle characteristics of masters sprint athletes would suggest both a reduced PCr metabolic capacity and a decreased rate of glycolysis and lactic acid formation in masters sprint athletes.. These changes in muscle characteristics would suggest both a reduced PCr metabolic capacity and a decreased rate of glycolysis and lactic acid formation. It is thus also possible that anaerobic energy production decreases with age due to reductions in key glycolytic enzymes, particularly PFK and phosphorylase which appear to be more highly concentrated in type II muscle fibers [73, 81]. The morphologic changes in type II fibers described above suggest the possibility that a decline in glycolytic enzyme activity with increasing age may contribute to the age-related decline in anaerobic performance observed in both aging sedentary individuals and masters athletes.

Data on age-related changes in the glycolytic pathway enzymes of aging sedentary individuals are equivocal $[6,17$, 
32, 33, 64, 115]. The cross-sectional study by Coggan and others [32] observed no differences in LDH, PFK, or phosphorylase activity in the gastrocnemius muscle of sedentary young (26 \pm 1 years) and older ( $64 \pm 1$ years) individuals. In contrast, a 5-year longitudinal study by Aniansson and others [6] observed a significant decrease in total LDH activity of vastus lateralis of men from the age of from 76 to 80 years of age. However, many of the subjects within this study not only increased activity levels over the 5-year period but were already physically training and not a sedentary population. However, more recent research also suggests that LDH activity is markedly decreased in older adults, at least from studies that have examined total LDH activity in abdominal muscles [80, 117]. Kaczor et al. [80] compared the LDH activity in the obliquus internus abdominis muscle of middle-aged (2954 years, $n=13)$ and older (61-74 years, $n=11)$ men and observed a highly significant $(p<0.0003)$ almost two-fold decrease in LDH activity expressed per gram of wet weight or relative to total protein content in the older group. However, while Pastoris and others [117] support this finding of decreased LDH activity in abdominal muscles, the same research team found no changes LDH activity in vastus lateralis or gluteus maximus muscles of 76 sedentary subjects ( 32 men, 44 women) between 15 and 91 years of age. This may suggest that the rate of change in glycolytic enzymes is significantly greater in muscle groups that are not load-bearing or prime movers with increasing age. Similarly, Coggan and others [33] obtained gastrocnemius muscle biopsy samples from eight young endurance runners ( $26 \pm 3$ years) and eight master athletes ( $63 \pm 6$ years) matched for volume, pace, and type of training as well as $10-\mathrm{km}$ running performance. While no difference was observed in fiber type distribution, LDH activity was significantly lower in the master athletes.

While total LDH activity does not appear to change with aging, there appears to be a shift in the relative proportion of the LDH isoenzymes. For example, Larsson [97] evaluated muscle biopsy tissue from 55 men (22-65 years), measuring total LDH and the components LDH-M and LDH-H. There was an age-related shift in the relative proportions of the two forms of the enzyme; LDH-M decreased significantly with LDH-H showing no significant change. An increase in relative activity of the LDH-H isoform may allow for greater oxidation of lactate, a function of type I muscle fiber, and may reflect a relative increase in type I fiber area with age [97] and/or an increase in the proportion of type I fiber number [97]. Thus, the majority of evidence supports maintenance of total LDH activity with a decrease in the M form and increase in the $\mathrm{H}$ form of LDH activity with aging in sedentary individuals.

In summary, the limited available data suggest that a decline in some glycolytic enzymes or changes in LDH isoform activity may contribute to the age-related decline in anaerobic performance observed in masters athletes.

\section{Accumulation of reaction products}

Anaerobic glycolysis is initiated at the beginning of maximal exercise when there is a need for greater reliance on ATP regeneration from both glycolysis and the phosphagen system than can be provided from mitochondrial sources [157]. During anaerobic exercise, there is an increase in both lactate and hydrogen ion $\left(\mathrm{H}^{+}\right)$concentration, and thus a decrease in $\mathrm{pH}$ within both the muscle cell and the blood. Thus, proton release from both the breakdown of ATP and lactic acid causes the acidosis of intense exercise [131]. The decrease in muscle $\mathrm{pH}$ causes both an increased need for $\mathrm{Ca}^{++}$for tension development, an inhibition of effective cross bridge cycling $[40,116]$, as well as an inhibition of enzymes involved with maximizing glycolytic flux [116], thus leading to a decrease in anaerobic performance.

Peak blood lactate concentration is widely used as an indirect measure of anaerobic glycolytic activity or capacity to discriminate between athletes of different glycolytic capacity and performance levels [92] and correlates with muscle lactate following maximal anaerobic performance $[31,72]$. In older sedentary men aged 60-70 years, peak blood lactate has been shown to be lower than young man aged $20-30$ years following a maximal 30 -s cycle ergometer test $[102,105]$.

In masters athletes, there appears to be an age-related decrease in peak blood lactate following both maximal sprint running [90] and swimming [14]. We have previously compared peak blood lactate values in male masters swimmers (28-80 years) following maximal $100 \mathrm{~m}$ freestyle swimming and found no effect of age on peak blood lactate [129]. However, we only had a total of 16 state-level masters swimmers, four subjects per 10-year age group, and one swimmer above 70 years of age and collected our lactates in a controlled noncompetitive pool environment. More recent studies on large numbers of high-performance masters swimmers (52 men and 56 women aged 4079 years) [14] and track sprinters (81 men and 75 women aged 35-88 years) [90] competing in international level competition have conclusively shown that peak blood lactate following maximal anaerobic exercise decreases with age. Both studies demonstrated that the peak blood lactate values observed were much higher than values reported for aged-matched sedentary men and women. Of interest is that in both male and female masters track sprinters [90] and male masters swimmers [14], the agerelated decline in both performance and blood lactate values was most evident after 70 years of age. Taken together, these data lend support to the theory that 
anaerobic glycolytic energy production declines with age, and this may be a contributing factor to the age-related decreases in anaerobic performance seen in many sports. Moreover, it appears that after 70 years of age, anaerobic glycolytic capacity is significantly reduced, secondary to decreases in muscle mass and type II fiber area, thus contributing to the curvilinear decrease in sports performance observed after that age.

It is well known that type II fibers exhibit higher activities of glycolytic enzymes and produce more lactic acid than type I fibers $[46,147]$ and that post-exercise lactate concentration depends on the total muscle mass engaged in the activity $[79,140]$. Thus, the well-observed age-related loss of muscle mass and shift toward a more oxidative muscle profile mediated by the atrophy of fast-twitch fibers in both aging sedentary $[26,39,122]$ and masters athletes $[67,84,88,123]$ may explain age-related decreases in blood lactate and as a result partly explain age-related decreases in anaerobic performance in masters athletes.

The $\mathrm{H}^{+}$ions from anaerobic glycolysis are partly buffered by the muscle buffer system including bicarbonate that is also present within the bloodstream [157]. Sprint training that stresses the anaerobic glycolytic system has been shown to increase buffering capacity and thus glycolytic capacity and sports performance in young athletes [44, 116, 134]. The limited data related to buffering capacity in older individuals suggest that there is a $6-7 \%$ increase in blood acidity and $12-16 \%$ reduction in blood bicarbonate concentration when comparing 80-year-old with 20-year-old sedentary individuals [51]. Within muscle, a recent study observed similar buffering capacity within young (20-35 years) and old (6580 years) sedentary man following a 60 -s maximal voluntary isometric contraction of the ankle dorsiflexor muscles, despite a lower $\mathrm{pH}$ and greater glycolytic rate in the younger men [93]. These data again suggest that older individuals rely more on oxidative pathways for ATP resynthesis during anaerobic performance, while younger persons rely more on the $\mathrm{PCr}$ and glycolytic pathways, possibly as a result of common finding of younger populations possessing a greater type II muscle fiber area compared to older individuals [32, 117], a common finding in both anaerobic [88, 126] and endurance $[67,85,126]$ masters athletes.

In summary, the limited available data suggest that both peak blood lactate and blood buffering capacity are compromised with aging in sedentary aging individuals. In anaerobic masters athletes, it appears that there is an age-related reduction in blood lactate production, possibly related to an age-related reduction in the type II muscle fiber area.

Aerobic energy system contribution

Age-related differences in the response of the aerobic energy system to the initiation of maximal exercise may also play a significant role in the observed age-related decline in maximal short-term work performance. In highly trained young athletes, the aerobic energy system contributes an increasingly greater percentage of overall energy demand the longer the anaerobic performance [42, 43, 59, $69,70,138]$. In young highly trained athletes, the aerobic contribution to $100 \mathrm{~m}$ sprint run events range between 3\% and $25 \%$ of overall energy demand and for the $200 \mathrm{~m}$ event between $14 \%$ and $33 \%$ [42, 59]. For $400 \mathrm{~m}$ track running events that stress the anaerobic glycolytic system, research suggests the aerobic contribution ranges between $28 \%$ and $64 \%$ depending on the method of measuring the aerobic contribution (accumulated oxygen deficit, blood lactate, $\mathrm{PCr}$ degradation, direct measurement of oxygen uptake, or mathematical modeling) [43, 59]. During all-out cycling exercise (e.g., Wingate test), early studies using breath-bybreath gas analysis estimated the aerobic contribution to 30 -s Wingate tests at between $14 \%$ and $29 \%[69,70]$. Separate work by Gastin and Lawson [60] used the measurement of accumulated oxygen deficit to estimate the aerobic system contribution to 30 -s all-out cycling at $30 \%$. The aerobic contribution increased to $73 \%$ and $91 \%$ for $60-$ and 90 -s all-out cycling, respectively. Thus, it appears that the longer the anaerobic performance, the greater the aerobic contribution to overall energy demands. Few studies have examined the aerobic contribution to anaerobic performance in older sedentary or masters athlete populations. Early work by Makrides and others [103] investigated 50 men and 50 women aged 15-71 years who performed a standard 30-s cycle test. Total work performed in $30 \mathrm{~s}$ declined linearly for both men and women by about $6 \% \cdot$ decade $^{-1}$ and was significantly related to both lean thigh volume estimated anthropometrically $(r=0.84)$ and $\mathrm{VO}_{2} \max (r=0.86)$. This latter finding strongly suggests that aerobic capacity is related to anaerobic performance in older individuals. In support of the suggestion that the aerobic system strongly contributes to anaerobic performance in older individuals is the finding that high-intensity endurance training in older sedentary individuals has been shown to significantly improve 30 -s maximal exercise capacity by $12.5 \%$ [102].

Importantly, the proportion of aerobic contribution to anaerobic energy metabolism is largely influenced by the initial speed of the $\mathrm{VO}_{2}$ response at the onset of exercise. Previously, Babcock and colleagues [9] reported that the speed of the $\mathrm{VO}_{2}$ response was slowed with aging in sedentary individuals but later demonstrated that physical training may speed the $\mathrm{VO}_{2}$ response in older populations [10]. More recently, DeLorey and colleagues [37, 38] reported that sedentary older individuals $(68 \pm 3$ years) demonstrated a slower $\mathrm{VO}_{2}$ response to both moderate and high-intensity (exercise compared to a younger (26士 3 years) cohort. However, concurrent training into older age 
has been shown to ameliorate the moderate-intensity $\mathrm{VO}_{2}$ response speed in sprint and endurance-trained athletes between the ages of 45-85 years [15]. From their work, Berger and colleagues [15] reported that sprint-trained masters athletes demonstrated slower $\mathrm{VO}_{2}$ responses than aged-matched endurance trained cohorts between 4655 years, 56-65 years, 66-75 years, and $>76$ years of age. Interestingly, the sprint-trained veteran athletes developed increasingly slowed $\mathrm{VO}_{2}$ responses as age increased between 56-65 and 66-75 years, while the endurancetrained athletes showed no effect of age. These findings suggest that aging sprint-trained athletes are likely to possess slowed $\mathrm{VO}_{2}$ response to exercise, which most likely reflects changes in muscle fiber characteristics and enzyme activities as discussed above. This slowed $\mathrm{VO}_{2}$ response may allow a smaller aerobic contribution to anaerobic exercise, which may either require greater anaerobic contribution to meet the energetic demands of the effort, or alternatively, decrease the power output to match the available energy resources, and in turn decrease performance.

In summary, given the importance of the aerobic contribution to anaerobic performance, it is possible that the lower $\mathrm{VO}_{2} \max$ of masters athletes $[25,121]$ and slower oxygen uptake responses [15] may contribute to the agerelated decreases in anaerobic performance observed in laboratory-based studies and sprint events from a range of sports.

\section{Heredity}

Athletic performance has long been recognized as having a strong heredity component [36, 101, 125]. Early genetic studies using young monozygotic (MZ) and dizygotic (DZ) twins suggested that up to $93 \%$ of aerobic capacity and $81 \%$ of anaerobic capacity may be genetically determined [82]. Later muscle biopsy studies on MZ and DZ twins identified that a major contributor to anaerobic performance, the relative percentage of fiber type, was $99.5 \%$ (men) and 93\% (women) genetically determined [87]. Similarly, other factors that may affect anaerobic performance including muscular strength and power [28, 50], peak blood lactate [82], and the anaerobic enzymes PFK and LDH [22] appear to have considerable genetic significance. Later work using different methodologies has suggested that many of the above factors that contribute to anaerobic performance are highly heritable including aerobic capacity (47\%) [20], 10- and 90-s maximal work outputs $(44-92 \%)$ [19, 135], 30-s work capacity (86\%) [83], muscular strength and mass [74], sprint running performance lasting less than $20 \mathrm{~s}$ [21], as well as the trainability of the anaerobic energy systems [19]. There is limited research examining the heritability of muscle strength and power in older populations [7, 150]. Arden and Spector [7] estimated that $46 \%$ of the variance in leg extensor power was accounted for by genetics in 45- to 70year-old female twins. Recent data from the Finnish Twin Study on Aging examined both the leg extensor power and isometric strength of $101 \mathrm{MZ}$ and $116 \mathrm{DZ}$ female twin pairs aged 63-76 years. Leg extensor power and strength shared a genetic component that explained $32 \%$ of the variance in leg power and $47 \%$ of the leg strength. Moreover, both leg power and strength had a nonshared environmental influence in common that accounted for $4 \%$ of the variance in power and $52 \%$ of the strength variance [151]. While no longitudinal studies to date have measured muscle power, the age effect of heritability of hand grip strength has been shown to be 52\% [52]. Moreover, during a 10-year follow-up of isometric hand grip strength in men, Carmelli and others [29] estimated the heritability to decrease from $35 \%$ to $22 \%$ from the ages of 63 to 73 years of age. In contrast, the shared environmental effects increased from $39 \%$ to $45 \%$. A more recent study by the same Finnish team [150] examined maximal walking speed and maximal leg extensor power and isometric strength in 217 twin pairs aged 63-76 years. Their genetic model suggested that strength, power, and walking speed had a common genetic effect which accounted for $52 \%$ of the variance in strength, $35 \%$ in leg power, and $34 \%$ in walking speed. Taken together, the above data suggest that many of the factors contributing to anaerobic performance in older persons are genetically predetermined but that exercise training can have a major influence on these factors into older age.

\section{Physical training}

Physical training for maximal anaerobic performance significantly enhances the capacity of both the ATP-PCr and glycolytic energy systems in younger individuals by influencing many of the factors above that effect anaerobic performance [13, 98, 132]. While the training adaptations that occur with sprint training have been less well documented than those of endurance training, it would appear that the following adaptations may occur: increased anaerobic capacity, muscle fiber hypertrophy of both the type I and II fibers, increased CK and glycolytic enzyme activity (phosphorylase, PFK, LDH), and improved anaerobic performance $[13,98,132]$.

While the effects of endurance training on previously sedentary older individuals have been well documented, there are few investigations examining the effects of anaerobic training in the same population. To date, only one study has examined changes in anaerobic capacity with high-intensity endurance training in the aged [102]. In 60 to 70 -year-old men that participated in interval training on a cycle ergometer at $50-85 \%$ of $\mathrm{VO}_{2}$ max three times per 
week for 12 weeks, there was a significant $12.5 \%$ increase in total work output and significant decrease in fatigue during a 30 -s anaerobic capacity test. Since the 30 -s test also has a significant aerobic contribution [70], it is possible that the observed increase in anaerobic capacity may have been partly attributable to a significant increase in $\mathrm{VO}_{2} \max$ in the same group following training.

In addition to the positive effects of high intensity endurance training on anaerobic performance, many studies have examined the effects of resistance training in previously sedentary older individuals. Adaptations to such training are likely to include muscle hypertrophy with an increase in the size of both type I and II muscle fibers [56, 66, 95], increased muscle shortening velocity [152], increased muscular force and specific muscle tension [55], muscular power [152], and increased neural activity as evidenced by large increases in electromyographic activity with minimal changes in muscle size [65].

To our knowledge, only two studies have specifically examined the effects of anaerobic or resistance training on anaerobic performance in masters athletes [34, 128]. We examined the effects of an 8-week hypertrophy resistance training program on muscular strength, thigh girth measured anthropometrically, and both 100 and $300 \mathrm{~m}$ sprint performance in eight high-performance male sprint runners aged 45-79 years who maintained their normal sprint training over the study period. Significant increases in both isoinertial and isokinetic strength, thigh girth, and 100- and $300-\mathrm{m}$ track performance following resistance training were observed [126]. More recently, Cristea and others [34] examined the effects of a 20 -week progressive and combined sprint and strength training program on muscle morphology and contractile characteristics in seven elite sprint runners (66 \pm 3 years) with no prior strength training experience. The researchers observed significant increases in isometric torque of the knee extensors (21\%) and flexors (40\%), 1-RM squat (27\%), squat jump (10\%), triple jump (4\%), reactive jump test power $(29 \%)$, rate of force development of braking (12\%) and propulsion (14\%), together with significant increases in $10 \mathrm{~m}$ sprint velocity (4\%) and $60 \mathrm{~m}$ sprint time (2\%). These performance changes were accompanied by a $9 \%$ increase in neural activity (iEMG) in the jump squat and hypertrophy of the type II (17\%) and IIA (20\%) fibers. The investigators concluded that the major adaptation to combined sprint and resistance training appears to be improved speed and power performance as a result of muscle hypertrophy, primarily of the muscle fibers expressing type II myosin heavy chain isoforms. Taken together, the results of the two studies above strongly suggest that resistance training combined with speed training enhances anaerobic performance in well-trained and motivated masters athletes.

\section{Conclusion}

There is limited research that has specifically examined anaerobic capacity and performance in masters athletes. From the data available, there appears no doubt that anaerobic performance declines linearly in older athletes to around $65-70$ years of age, after which the decline in anaerobic performance accelerates. While the actual mechanisms explaining these declines remain to be elucidated, any number of factors contributing to anaerobic performance appears to contribute. The consensus of research suggests that decreased muscle mass, type II muscle fiber atrophy, and a shift towards a greater expression of the MHC I isoform in older age, together with the effect these changes have on many other factors (i.e. fiber contractile velocity, enzyme activity, lactate production) are the major contributors to the age-related decline in anaerobic performance in masters athletes. It also appears that high-intensity sprint training, combined with hypertrophy resistance training, may potentially slow the decline in anaerobic performance of masters athletes into older age.

\section{References}

1. Aagaard P, Magnusson PS, Larsson B, Kjaer M, Krustrup P (2007) Mechanical muscle function, morphology, and fiber type in lifelong trained elderly. Med Sci Sports Exerc 39:19891996

2. Abe T, Kumagai K, Brechue WF (2000) Fascicle length of leg muscles is greater in sprinters than distance runners. Med Sci Sports Exerc 32:1125-1129

3. Alway SE, Siu PM, Murlasits Z, Butler DC (2005) Muscle hypertrophy models: applications for research on aging. Can J Appl Physiol 30:591-624

4. Andersen JL (2003) Muscle fibre type adaptation in the elderly human muscle. Scand J Sci Med Sports 13:40-47

5. Aniansson A, Grimby G, Rundgren A, Svanborg A, Oerlander J (1980) Physical training in old men. Age Ageing 9:186-187

6. Aniansson A, Hedberg M, Henning GB, Grimby G (1986) Muscle morphology, enzymatic activity, and muscle strength in elderly men: a follow-up study. Muscle Nerve 9:585-591

7. Arden NK, Spector TD (1997) Genetic influences on muscle strength, lean body mass, and bone mineral density: a twin study. J Bone Miner Res 12:2076-2081

8. Arslan C (2005) Relationship between the 30-second wingate test and characteristics of isometric and explosive leg strength in young subjects. J Strength Cond Res 19:658-666

9. Babcock MA, Paterson DH, Cunningham DA (1992) Influence of ageing on aerobic parameters determined from a ramp test. Eur J Appl Physiol Occup Physiol 65:138-143

10. Babcock MA, Paterson DH, Cunningham DA (1994) Effects of aerobic endurance training on gas kinetics of older men. Med Sci Sports Exerc 26:447-452

11. Baker AB, Tang YQ, Turner MJ (2003) Percentage decline in Masters superathlete track and field performance with aging. Exp Aging Res 29:47-65

12. Bar-Or O (1987) The Wingate anaerobic test. An update on methodology, reliability and validity. Sports Med 4:381-394 
13. Barnett C, Carey M, Proietto J, Cerin E, Febbraio MA, Jenkins D (2004) Muscle metabolism during sprint exercise in man: influence of sprint training. J Sci Med Sport 7:314-322

14. Benelli P, Ditroilo M, Forte R, De Vito G, Stocchi V (2007) Assessment of post-competition peak blood lactate in male and female master swimmers aged 40-79 years and its relationship with swimming performance. Eur J Appl Physiol 99:685-693

15. Berger NJA, Rittweger J, Kwiet A, Michaelis I, Williams AG, Tolfrey K, Jones AM (2006) Pulmonary $\mathrm{O}_{2}$ uptake on-kinetics in endurance- and sprint-trained master athletes. Int J Sports Med 32:383-393

16. Blazevich A (2006) Effects of physical training and detraining, immobilisation, growth and aging on human fascicle geometry. Sports Med 36:1003-1017

17. Borges O, Essen-Gustavsson B (1989) Enzyme activities in type I and II muscle fibres of human skeletal muscle in relation to age and torque development. Acta Physiol Scand 136:29-36

18. Bortz WM IV, Bortz WM II (1996) How fast do we age? Exercise performance over time as a biomarker. J Gerontol Med Sci 51:M223-M225

19. Bouchard C, Dionne FT, Simoneau JA, Boulay MR (1992) Genetics of aerobic and anaerobic performances. Exerc Sport Sci Rev 20:27-58

20. Bouchard C, Lesage R, Lortie G, Simoneau JA, Hamel P, Boulay MR, Perusse L, Theriault G, Leblanc C (1986) Aerobic performance in brothers, dizygotic and monozygotic twins. Med Sci Sports Exerc 18:639-646

21. Bouchard C, Malina RM (1983) Genetics of physiological fitness and motor performance. Exerc Sport Sci Rev 11:306-339

22. Bouchard C, Simoneau JA, Lortie G, Boulay MR, Marcotte M, Thibault MC (1986) Genetic effects in human skeletal muscle fiber type distribution and enzyme activities. Can J Physiol Pharmacol 64:1245-1251

23. Bouchard C, Taylor AW, Simoneau JA, Dulac S. Testing anaerobic power and capacity. In: Physiological testing of the high performance athlete, Champaign, Ill., Human Kinetics Books, c1991, p. 175-221. 1991: United States

24. Brechue WF, Abe T (2002) The role of FFM accumulation and skeletal muscle architecture in powerlifting performance. Eur J Appl Physiol 86:327-336

25. Brown SJ, Ryan HJ, Brown JA (2007) Age-associated changes in $\mathrm{VO}_{2}$ and power output - a cross-sectional study of endurance trained New Zealand cyclists. J Sports Sci Med 6:477-483

26. Brunner F, Schmid A, Sheikhzadeh A, Nordin M, Yoon J, Frankel V (2007) Effects of aging on type II muscle fibers: a systematic review of the literature.. J Aging Phys Act 15:336348

27. Cadefau J, Casademont J, Grau JM, Fernandez J, Balaguer A, Vernet M, Cusso R, Urbano-Marquez A (1990) Biochemical and histochemical adaptation to sprint training in young athletes. Acta Physiol Scand 140:341-351

28. Calvo M, Rodas G, Vallejo M, Estruch A, Arcas A, Javierre C, Viscor G, Ventura JL (2002) Heritability of explosive power and anaerobic capacity in humans. Eur J Appl Physiol 86:218-225

29. Carmelli D, Reed T (2000) Stability and change in genetic and environmental influences on hand-grip strength in older male twins. J Appl Physiol 89:1879-1883

30. Cartee GD (1994) Influence of age on skeletal muscle glucose transport and glycogen metabolism. Med Sci Sports Exerc 26:577-585

31. Cheetham ME, Boobis LH, Brooks S, Williams C (1986) Human muscle metabolism during sprint running. J Appl Physiol 61:54-60

32. Coggan AR, Spina RJ, King DS, Rogers MA, Brown M, Nemeth PM, Holloszy JO (1992) Histochemical and enzymatic comparison of the gastrocnemius muscle of young and elderly men and women. J Gerontol 47:B71-B76
33. Coggan AR, Spina RJ, Rogers MA, King DS, Brown M, Nemeth PM, Holloszy JO (1990) Histochemical and enzymatic characteristics of skeletal muscle in masters athletes. J Appl Physiol 68:1896-1901

34. Cristea A, Korhonen MT, Hakkinen K, Mero A, Alen M, Sipila S, Viitasalo JT, Koljonen MJ, Suominen H, Larsson L (2008) Effects of combined strength and sprint training on regulation of muscle contraction at the whole-muscle and single-fibre levels in elite master sprinters. Acta Physiol (Oxf) 193:275-289

35. D’Antona G, Lanfranconi F, Pellegrino MA, Brocca L, Adami R, Rossi R, Moro G, Miotti D, Canepari M, Bottinelli R (2006) Skeletal muscle hypertrophy and structure and function of skeletal muscle fibres in male body builders. J Physiol 570:611-627

36. Davids K, Baker J (2007) Genes, environment and sport performance. Sports Med 37:961-980

37. DeLorey DS, Kowalchuk JM, Paterson DH (2003) Relationship between pulmonary $\mathrm{O}_{2}$ uptake kinetics and muscle deoxygenation during moderate-intensity exercise. J Appl Physiol 95:113120

38. DeLorey DS, Kowalchuk JM, Paterson DH (2005) Adaptation of pulmonary $\mathrm{O}_{2}$ uptake kinetics and muscle deoxygenation at the onset of heavy-intensity exercise in young and older adults. J Appl Physiol 98:1697-1704

39. Deschenes MR (2004) Effects of aging on muscle fibre type and size. Sports Med 34:809-824

40. Donaldson SK, Hermansen L, Bolles L (1978) Differential, direct effects of $\mathrm{H}^{+}$on $\mathrm{Ca}_{2}{ }^{+}$-activated force of skinned fibers from the soleus, cardiac and adductor magnus muscles of rabbits. Pflugers Arch 376:55-65

41. Donato AJ, Tench K, Glueck DH, Seals DR, Eskurza I, Tanaka H (2003) Declines in physiological functional capacity with age: a longitudinal study in peak swimming performance. J Appl Physiol 94:764-769

42. Duffield R, Dawson B, Goodman C (2004) Energy system contribution to $100-\mathrm{m}$ and $200-\mathrm{m}$ track running events. J Sci Med Sport 7:302-313

43. Duffield R, Dawson B, Goodman C (2005) Energy system contribution to 400 -metre and 800-metre track running. J Sports Sci 23:299-307

44. Edge J, Bishop D, Hill-Haas S, Dawson B, Goodman C (2006) Comparison of muscle buffer capacity and repeated-sprint ability of untrained, endurance-trained and team-sport athletes. Eur J Appl Physiol 96:225-234

45. Essen-Gustavsson B, Borges O (1986) Histochemical and metabolic characteristics of human skeletal muscle in relation to age. Acta Physiol Scand 126:107-111

46. Essen B, Haggmark T (1975) Lactate concentration in type I and II muscle fibres during muscular contraction in man. Acta Physiol Scand 95:344-346

47. Essen B, Jansson E, Henriksson J, Taylor AW, Saltin B (1975) Metabolic characteristics of fibre types in human skeletal muscle. Acta Physiol Scand 95:153-165

48. Fair RC (2007) Estimated age effects in athletic events and chess. Exp Aging Res 33:37-57

49. Faulkner JA, Larkin LM, Claflin DR, Brooks SV (2007) Agerelated changes in the structure and function of skeletal muscles. Clin Exp Pharmacol Physiol 34:1091-1096

50. Forbes GB, Sauer EP, Weitkamp LR (1995) Lean body mass in twins. Metabolism 44:1442-1446

51. Frassetto L, Sebastian A (1996) Age and systemic acid-base equilibrium: analysis of published data. J Gerontol A Biol Sci Med Sci 51:B91-B99

52. Frederiksen H, Gaist D, Petersen HC, Hjelmborg J, McGue M, Vaupel JW, Christensen K (2002) Hand grip strength: a 
phenotype suitable for identifying genetic variants affecting midand late-life physical functioning. Genet Epidemiol 23:110-122

53. Frontera WR, Hughes VA, Fielding RA, Fiatarone MA, Evans WJ, Roubenoff R (2000) Aging of skeletal muscle: a 12-year longitudinal study. J Appl Physiol 71:644-650

54. Frontera WR, Hughes VA, Fielding RA, Fiatarone MA, Evans WJ, Roubenoff R (2000) Aging of skeletal muscle: a 12-yr longitudinal study. J Appl Physiol 88:1321-1326

55. Frontera WR, Hughes VA, Krivickas LS, Kim SK, Foldvari M, Roubenoff R (2003) Strength training in older women: early and late changes in whole muscle and single cells. Muscle Nerve 28:601-608

56. Frontera WR, Meredith CN, O'Reilly KP, Knuttgen HG, Evans WJ (1988) Strength conditioning in older men: skeletal muscle hypertrophy and improved function. J Appl Physiol 64:10381044

57. Frontera WR, Reid KF, Phillips EM, Krivickas LS, Hughes VA, Roubenoff R, Fielding RA (2008) Muscle fiber size and function in elderly humans: a longitudinal study. J Appl Physiol 105 (2):637-642

58. Fung L, Ha A (1994) Changes in track and field performance with chronological aging. Int J Aging Hum Devel 38:171-180

59. Gastin PB (2001) Energy system interaction and relative contribution during maximal exercise. Sports Med 31:725-741

60. Gastin PB, Lawson DL (1994) Influence of training status on maximal accumulated oxygen deficit during all-out cycle exercise. Eur J Appl Physiol Occup Physiol 69:321-330

61. Gatta G, Benelli P, Ditrolio M (2006) The decline of swimming performance with advancing age: a cross-sectional study. J Strength Cond Res 20:932-938

62. Gratas-Delamarche A, Le Cam R, Delamarche P, Monnier M, Koubi H (1994) Lactate and catecholamine responses in male and female sprinters during a Wingate test. Eur J Appl Physiol Occup Physiol 68:362-366

63. Greenhaff PL, Nevill ME, Soderlund K, Bodin K, Boobis LH, Williams C, Hultman E (1994) The metabolic responses of human type I and II muscle fibres during maximal treadmill sprinting. J Physiol 478:149-155

64. Grimby G, Danneskiold-Samsoe B, Hvid K, Saltin B (1982) Morphology and enzymatic capacity in arm and leg muscles in 78-81 year old men and women. Acta Physiol Scand 115:125134

65. Hakkinen K, Alen M, Kallinen M, Newton RU, Kraemer WJ (2000) Neuromuscular adaptation during prolonged strength training, detraining and re-strength-training in middle-aged and elderly people. Eur J Appl Physiol 83:51-62

66. Hakkinen K, Kallinen M, Izquierdo M, Jokelainen K, Lassila H, Malkia E, Kraemer WJ, Newton RU, Alen M (1998) Changes in agonist-antagonist EMG, muscle CSA, and force during strength training in middle-aged and older people. J Appl Physiol 84:1341-1349

67. Harridge S, Magnusson G, Saltin B (1997) Life-long endurancetrained elderly men have high aerobic power, but have similar muscle strength to non-active elderly men. Aging 9:80-87

68. Hartely AA, Hartely JT (1986) Age differences and changes in sprint swimming performances of masters athletes. Exp Aging Res 12:65-70

69. Hill DW (1999) Energy system contributions in middle-distance running events. J Sports Sci 17:477-483

70. Hill DW, Smith JC (1992) Calculation of aerobic contribution during high intensity exercise. Res Q Exerc Sport 63:85-88

71. Hill DW, Smith JC (1993) Gender difference in anaerobic capacity: role of aerobic contribution. Br J Sports Med 27:45-48

72. Hirvonen J, Nummela A, Rusko H, Rehunen S, Haerkoenen M (1992) Fatigue and changes of ATP, creatine phosphate, and lactate during the 400-m sprint. Can J Sport Sci 17:141-144
73. Hunter SK, Thompson MW, Ruell PA, Harmer AR, Thom JM, Gwinn TH, Adams RD (1999) Human skeletal sarcoplasmic reticulum $\mathrm{Ca}^{2}+$ uptake and muscle function with aging and strength training. J Appl Physiol 86:1858-1865

74. Huygens W, Thomis MA, Peeters MW, Vlietinck RF, Beunen GP (2004) Determinants and upper-limit heritabilities of skeletal muscle mass and strength. Can J Appl Physiol 29:186-200

75. Jacobs I, Bar-Or O, Karlsson J, Dotan R, Tesch P (1982) Changes in muscle metabolites in females with 30 -s exhaustive exercise. Med Sci Sports Exerc 14:457-460

76. Janssen I, Heymsfield SB, Ross R (2002) Low relative skeletal muscle mass (sarcopenia) in older persons is associated with functional impairment and physical disability. J Am Geriatr Soc 50:889-896

77. Janssen I, Heymsfield SB, Wang Z, Ross R (2000) Skeletal muscle mass and distribution in 468 men and women aged 18 88 yr. J Appl Physiol 89:81-95

78. Jaworowski A, Porter MM, Holmback AM, Downham D, Lexell $J$ (2002) Enzyme activities in the tibialis anterior muscle of young moderately active men and women: relationship with body composition, muscle cross-sectional area and fibre type composition. Acta Physiol Scand 176:215-225

79. Jensen-Urstad M, Svedenhag J, Sahlin K (1994) Effect of muscle mass on lactate formation during exercise in humans. Eur J Appl Physiol Occup Physiol 69:189-195

80. Kaczor JJ, Ziolkowski W, Antosiewicz J, Hac S, Tarnopolsky MA, Popinigis J (2006) The effect of aging on anaerobic and aerobic enzyme activities in human skeletal muscle. J Gerontol A Biol Sci Med Sci 61A:339-344

81. Keh-Evans L, Rice CL, Noble EG, Paterson DH, Cunningham DA, Taylor AW (1992) Comparison of histochemical, biochemical, and contractile properties of triceps surae of trained aged subjects. Can J Aging 11:412-425

82. Klissouras V (1971) Heritability of adaptive variation. J Appl Physiol 31:338-44

83. Klissouras V (1997) Heritability of adaptive variation: an old problem revisited. J Sports Med Phys Fitness 37:1-6

84. Klitgaard H, Ausoni S, Damiani E (1989) Sarcoplasmic reticulum of human skeletal muscle: age-related changes and effect of training. Acta Physiol Scand 137:23-31

85. Klitgaard H, Brunet A, Marc R, Monod H, Mantoni M, Saltin B (1989) The aging skeletal muscle: effect of training on muscle force and mass. Int J Sports Med 10:S93-S94

86. Klitgaard H, Mantoni M, Schiaffino S, Ausoni S, Gorza L, Laurent-Winter C, Schnohr P, Saltin B (1990) Function, morphology and protein expression of ageing skeletal muscle: a cross-sectional study of elderly men with different training backgrounds. Acta Physiol Scand 140:41-54

87. Komi PV, Viitasalo JH, Havu M, Thorstensson A, Sjodin B, Karlsson J (1977) Skeletal muscle fibres and muscle enzyme activities in monozygous and dizygous twins of both sexes. Acta Physiol Scand 100:385-392

88. Korhonen MT, Cristea A, AlÃ@n M, HÃ akkinen K, SipilÃa S, Mero A, Viitasalo JT, Larsson L, Suominen H (2006) Aging, muscle fiber type, and contractile function in sprint-trained athletes. J Appl Physiol 101:906-917

89. Korhonen MT, Mero A, Suominen H (2003) Age-related differences in 100-m sprint performance in male and female master runners. Med Sci Sports Exerc 35:1419-1428

90. Korhonen MT, Suominen H, Mero A (2005) Age and sex differences in blood lactate response to sprint running in elite master athletes. Can J Appl Physiol 30:649-665

91. Krivickas LS, Suh D, Wilkins J, Hughes VA, Roubenoff R, Frontera WR (2001) Age- and gender-related differences in maximum shortening velocity of skeletal muscle fibers. Am J Phys Med Rehab 80:447-455 
92. Lacour JR, Bouvat E, Barthelemy JC (1990) Post-competition blood lactate concentrations as indicators of anaerobic energy expenditure during 400-m and 800-m races. Eur J Appl Physiol Occup Physiol 61:172-176

93. Lanza IR, Befroy DE, Kent-Braun JA (2005) Age-related changes in ATP-producing pathways in human skeletal muscle in vivo. J Appl Physiol 99:1736-1744

94. Larsson L (1978) Morphological and functional characteristics of the ageing skeletal muscle in man: a cross-sectional study. Acta Physiol Scand 457:1-36

95. Larsson L (1982) Physical training effects on muscle morphology in sedentary males at different ages. Med Sci Sports Exerc 14:203-206

96. Larsson L, Gimby G, Karlsson J (1979) Muscle strength and speed of movement in relation to age and muscle morphology. J Appl Physiol 46:451-456

97. Larsson L, Sjodin B, Karlsson J (1978) Histochemical and biochemical changes in human skeletal muscle with age in sedentary males, age 22-65 years. Acta Physiol Scand 103:31-39

98. Levesque M, Boulay MR, Bouchard C, Simoneau JA (1997) Time course of training-induced changes in maximal exercise of short duration in men and women. Int J Sports Med 18:464-469

99. Lexell J (1995) Human aging, muscle mass, and fiber type composition. J Gerontol A Biol Sci Med Sci 2:253-265

100. Lexell J, Taylor CC, Sjostrom M (1988) What is the cause of the ageing atrophy? Total number, size and proportion of different fibre types studied in whole vastus lateralis muscle from 15- to 83-year-old men. J Neurol Sci 84:275-294

101. MacArthur DG, North KN (2007) ACTN3: a genetic influence on muscle function and athletic performance. Exerc Sport Sci Rev 35:30-34

102. Makrides L, Heigenhauser GJ, Jones NL (1990) High-intensity endurance training in 20- to 30- and 60- to 70-yr-old healthy men. J Appl Physiol 69:1792-1798

103. Makrides L, Heigenhauser GJ, McCartney N, Jones NL (1985) Maximal short term exercise capacity in healthy subjects aged 15-70 years. Clin Sci (Lond) 69:197-205

104. Maron BJ, Araujo CGS, Thompson PD, Fletcher GF, Bayes de Luna A, Fleg JL, Pelliccia A, Balady GJ, Furlanello F, Van Camp SP, Elosua R, Chaitman BR, Bazzarre TL (2001) Recommendations for preparticipation screening and the assessment of cardiovascular disease in Masters Athletes. Circulation 103:327-334

105. Marsh GD, Paterson DH, Govindasamy D, Cunningham DA (1999) Anaerobic power of the arms and legs of young and older men. Exp Physiol 84:589-597

106. McCall GE, Byrnes WC, Dickinson AL, Fleck SJ (1998) Sample size required for the accurate determination of fiber area and capillarity of human skeletal muscle. Can J Appl Physiol 23:594-599

107. McCartney N, Spriet LL, Heigenhauser GJ, Kowalchuk JM, Sutton JR, Jones NL (1986) Muscle power and metabolism in maximal intermittent exercise. J Appl Physiol 60:1164-1169

108. McCully KK, Fielding RA, Evans WJ, Leigh JS Jr, Posner JD (1993) Relationships between in vivo and in vitro measurements of metabolism in young and old human calf muscles. J Appl Physiol 75:813-819

109. Meredith CN, Frontera WR, Fisher EC, Hughes VA, Herland JC, Edwards J, Evans WJ (1989) Peripheral effects of endurance training in young and old subjects. J Appl Physiol 66:2844-2849

110. Miller AEJ, MacDougall JD, Tarnopolsky MA, Sale DG (1993) Gender differences in strength and muscle fiber characteristics. Eur J Appl Physiol Occup Physiol 66:254-262

111. Moller P, Bergstrom J, Furst P, Hellstrom K (1980) Effect of aging on energy-rich phosphagens in human skeletal muscles. Clin Sci (Lond) 58:553-555
112. Moller P, Brandt R (1982) The effect of physical training in elderly subjects with special reference to energy-rich phosphagens and myoglobin in leg skeletal muscle. Clin Physiol 2:307314

113. Moore DH (1975) A study of group track and field records to relate age and running speed. Nature 253:264-265

114. Nessel EH (2004) The physiology of aging as it relates to sports. JAMA 17:12-17

115. Orlander J, Kiessling KH, Larsson L, Karlsson J, Aniansson A (1978) Skeletal muscle metabolism and ultrastructure in relation to age in sedentary men. Acta Physiologica Scandinavica 104:249-261

116. Parkhouse WS, McKenzie DC (1984) Possible contribution of skeletal muscle buffers to enhanced anaerobic performance: a brief review. Med Sci Sports Exerc 16:328-338

117. Pastoris O, Boschi F, Verri M, Baiardi P, Felzani G, Vecchiet J, Dossena M, Catapano M (2000) The effects of aging on enzyme activities and metabolite concentrations in skeletal muscle from sedentary male and female subjects. Exp Gerontol 35:95-104

118. Paterson DH, Jones GR, Rice CL (2007) Ageing and physical activity: evidence to develop exercise recommendations for older adults. Can J Public Health 98:S69-S108

119. Pearson SJ, Young A, Macaluso A, Devito G, Nimmo MA, Cobbold M, Harridge SD (2002) Muscle function in elite master weightlifters. Med Sci Sports Exerc 34:1199-1206

120. Perez-Gomez J, Rodriguez GV, Ara I, Olmedillas H, Chaverren J, Gonzalez-Henriquez JJ, Dorado C, Calbert CA (2008) Role of muscle mass on sprint performance: gender differences? Eur J Appl Physiol 102:685-694

121. Pollock ML, Foster C, Knapp D, Rod JL, Schmidt DH (1987) Effect of age and training on aerobic capacity and body composition of Masters athletes. J Appl Physiol 62:725731

122. Porter MM, Vandervoort AA, Lexell J (1995) Aging of human muscle: structure, function and adaptability. Med Sci Sports Exerc 5:129-142

123. Proctor DN, Sinning WE, Walro JM, Sieck GC, Lemon PWR (1995) Oxidative capacity of human muscle fibre types: effects of age and training status. J Appl Physiol 78:2033-2038

124. Rahe RH, Arthur RJ (1975) Swim performance decrement over middle life. Med Sci Sports 7:53-58

125. Rankinen T, Bray MS, Hagberg JM, Perusse L, Roth SM, Wolfarth B, Bouchard C (2006) The human gene map for performance and health-related fitness phenotypes: the 2005 update. Med Sci Sports Exerc 38:1863-1888

126. Reaburn P (1994) The lifetime athlete - physical work capacities and skeletal muscle characteristics. The University of Queensland, Brisbane

127. Reaburn P, Dascombe BJ (2008) Endurance performance in Masters athletes. Eur Rev Aging Phys Act 5:31-42

128. Reaburn P, Logan P, Mackinnon L. The effect of hypertrophy resistance training on anaerobic work capacity in veteran sprint runners. In: 1994 the year of the coach: National Coaching Conference proceedings, Canberra, 1 to 3 December 1994, Canberra, Australian Coaching Council, 1994, p. 168-172. 1994. Australia.

129. Reaburn PR, Mackinnon LT (1990) Blood lactate responses in older swimmers during active and passive recovery following maximal sprint swimming. Eur J Appl Physiol Occup Physiol 61:246-250

130. Rehman HU, Masson EA (2005) Neuroendocrinology of female aging. Gend Med 2:41-56

131. Robergs RA, Ghiasvand F, Parker D (2004) Biochemistry of exercise-induced metabolic acidosis. Am J Physiol Regul Integr Comp Physiol 287:R502-R516 
132. Ross A, Leveritt M (2001) Long-term metabolic and skeletal muscle adaptations to short-sprint training: implications for sprint training and tapering. Sports Med 31:1063-1082

133. Schalin-Jantti C, Laurila E, Lofman M, Groop LC (1995) Determinants of insulin-stimulated skeletal muscle glycogen metabolism in man. Eur J Clin Invest 25:693-698

134. Sharp RL, Costill DL, Fink WJ, King DS (1986) Effects of eight weeks of bicycle ergometer sprint training on human muscle buffer capacity. Int J Sports Med 7:13-17

135. Simoneau JA, Lortie G, Boulay MR, Marcotte M, Thibault MC, Bouchard C (1986) Inheritance of human skeletal muscle and anaerobic work capacity adaptation to high-intensity intermittent training. Int J Sports Med 7:167-171

136. Sjodin B (1992) Anaerobic function. Sport Sci Rev 1:13-27

137. Slade JM, Miszko TA, Laity JH, Agrawal SK, Cress ME (2002) Anaerobic power and physical function in strength-trained and non-strength-trained older adults. J Gerontol A Biol Sci Med Sci 57:M168-M172

138. Spencer MR, Gastin PB (2001) Energy system contribution during 200- to 1500-m running in highly trained athletes. Med Sci Sports Exerc 33:157-162

139. Spurway N (2006) Top-down studies of the genetic contribution to differences in physical capacity. In: Spurway N, Wackerhage $\mathrm{H}$ (eds) Genetics and molecular biology of muscle adaptation. Churchill Livingstone Elsevier, BASES, London, pp 25-59

140. Stainsby WN, Brooks GA (1990) Control of lactic acid metabolism in contracting muscles and during exercise. Exerc Sport Sci Rev 18:29-63

141. Steinhagen-Thiessen E, Hilz H (1976) The age-dependent decrease in creatine kinase and aldolase activities in human striated muscle is not caused by an accumulation of faulty proteins. Mech Ageing Dev 5:447-457

142. Stones MJ, Kozma A (1981) Adult age trends in athletic performances. Exp Aging Res 7:269-280

143. Sui X, Hooker SP, Lee IM, Church TS, Colabianchi N, Lee CD, Blair SN (2008) A prospective study of cardiorespiratory fitness and risk of Type 2 diabetes in women. Diabetes Care 31:550-555

144. Tanaka H, Seals DR (1997) Age and gender interactions in physiological functional capacity: insight from swimming performance. J Appl Physiol 82:846-851

145. Tanaka H, Seals DR (2003) Dynamic exercise performance in Masters athletes: insight into the effect of primary human aging on physiological functional capacity. J Appl Physiol 95:21522162

146. Tanaka H, Seals DR (2008) Endurance exercise performance in Masters athletes: age-associated changes and underlying physiological mechanisms. J Physiol 586:55-63

147. Tesch P, Sjodin B, Karlsson J (1978) Relationship between lactate accumulation, $\mathrm{LDH}$ activity, $\mathrm{LDH}$ isozyme and fibre type distribution in human skeletal muscle. Acta Physiol Scand 103:40-46

148. Tesch PA, Thorsson A, Fujitsuka N (1989) Creatine phosphate in fiber types of skeletal muscle before and after exhaustive exercise. J Appl Physiol 66:1756-1759

149. Thom JM, Morse CI, Birc KM, Narici MV (2007) Influence of muscle architecture on the torque and power-velocity characteristics of young and elderly men. Eur J Appl Physiol 100:613619

150. Tiainen K, Pajala S, Sipil S, Kaprio J, Koskenvuo M, AlÃ $\subset n$ M, Heikkinen E, Tolvanen A, Rantanen T (2007) Genetic effects in common on maximal walking speed and muscle performance in older women. Scand J Sci Med Sports 17:274280

151. Tiainen K, Sipila S, Alen M, Heikkinen E, Kaprio J, Koskenvuo M, Tolvanen A, Pajala S, Rantanen T (2005) Shared genetic and environmental effects on strength and power in older female twins. Med Sci Sports Exerc 37:72-78

152. Trappe S, Williamson D, Godard M, Porter D, Rowden G, Costill D (2000) Effect of resistance training on single muscle fiber contractile function in older men. J Appl Physiol 89:143152

153. Trappe SW, Costill DL, Vukovich MD, Jones J, Melham T (1996) Aging among elite distance runners: a 22-yr longitudinal study. J Appl Physiol 80:285-290

154. Weber CL, Schneider DA (2000) Maximal accumulated oxygen deficit expressed relative to the active muscle mass for cycling in untrained male and female subjects. Eur J Appl Physiol 82:255261

155. Weber CL, Schneider DA (2002) Increases in maximal accumulated oxygen deficit after high-intensity interval training are not gender dependent. J Appl Physiol 92:1795-1801

156. Weyand PG, Cureton KJ, Conley DS, Higbie EJ (1993) Peak oxygen deficit during one- and two-legged cycling in men and women. Med Sci Sports Exerc 25:584-591

157. Wilmore J, Costill D, Kenney WL (2008) Physiology of sport and exercise, 4th edn. Human Kinetics, Chicago, Illinois

158. Wright VJ, Perricelli BC (2008) Age-related rates of decline in performance among elite senior athletes. Am J Sports Med $36: 441-442$

159. Young A, Stokes M, Crowe M (1984) Size and strength of the quadriceps muscles of old and young women. Eur J Clin Invest 14:282-287

160. Young A, Stokes M, Crowe M (1985) The size and strength of the quadriceps muscles of old and young men. Clin Physiol 5:145-154

161. Yu F, Hedstram M, Cristea A, Dalcon N, Larsson L (2007) Effects of ageing and gender on contractile properties in human skeletal muscle and single fibres. Acta Physiol 190:229-241 